\title{
El turismo y la geografía. Entrevista realizada al Mgs. Prof. Rodolfo Bertoncello(1)
}

\author{
Mariela Demarchi (2)
}

Margarita Valiente ${ }^{(3)}$

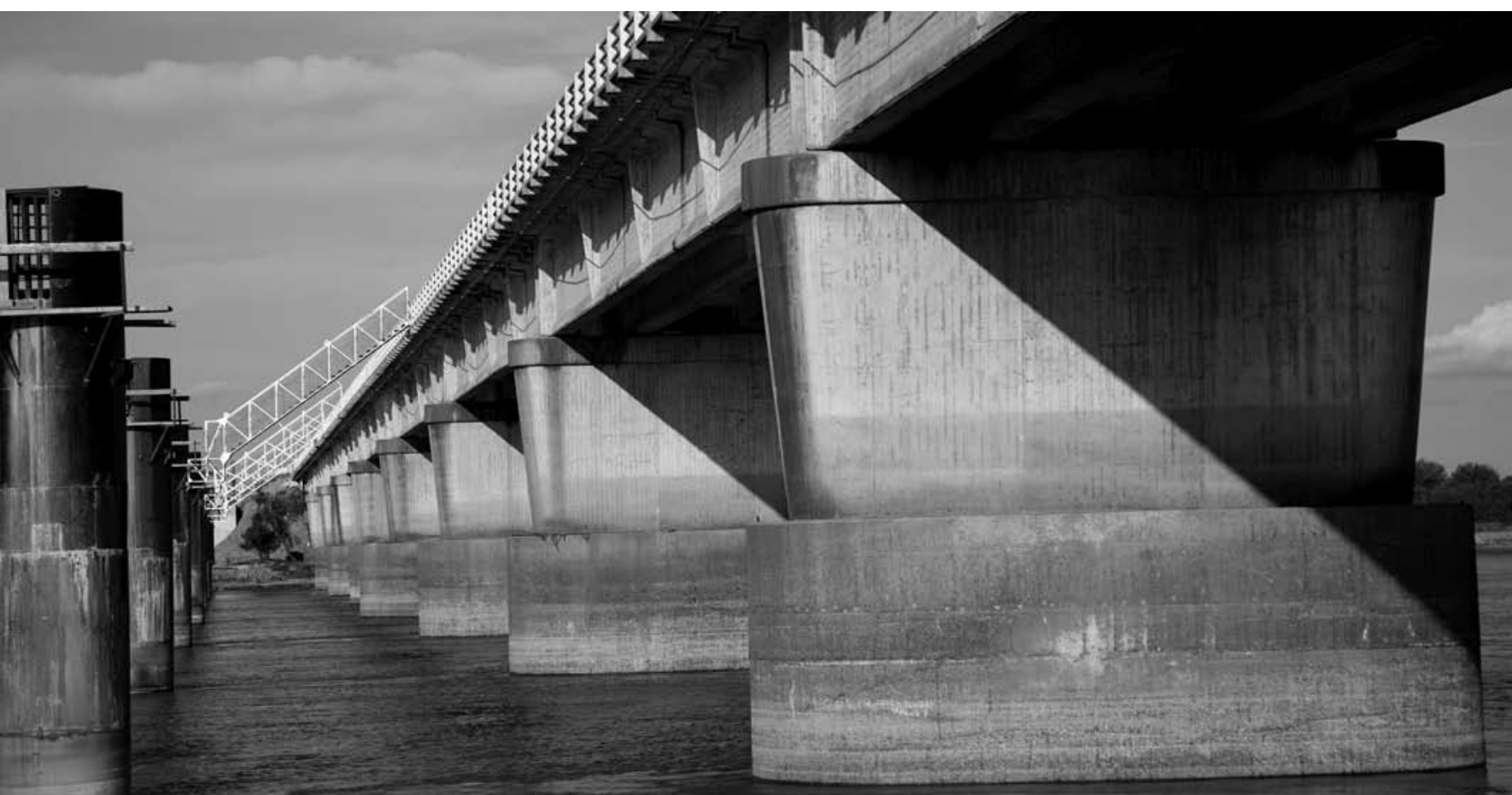

(1) Docente Titular de Geografía Social de la UBA e investigador independiente del CONICET. Director del Grupo de Estudios en Turismo y Territorio con sede en el
Instituto de Geografía de la UBA.

(2) Docente de la cátedra Problemáticas Territoriales Americanas y Geografía de Santa Fe. FHUC. UNL.
E-mail: demarchi@hotmail.com (3) Docente Práctica Docente en Geografía de la Facultad de Humanidades y Ciencias de la UNL.

E-mail: mvpaoli@hotmail.com 
Durante el desarrollo del IV Congreso Nacional sobre Problemáticas Sociales Contemporáneas, que se llevó a cabo en la Facultad de Humanidades y Ciencias -UNL-, en octubre del 2008, se realizó la entrevista al destacado geógrafo, quien fue consultado sobre temáticas relacionadas con el turismo y la geografía.

\section{¿Cuál es el sentido del vínculo entre turismo y Ciencias Sociales?}

Si se considera al turismo como una práctica social en sentido amplio, evitando la visión restringida (y dominante) que sólo lo ve como una actividad económica, el vínculo es claro y amplio. El turismo involucra dimensiones políticas, sociales, culturales, económicas o territoriales, y todas ellas pueden ser objeto de indagación tomando como base los marcos interpretativos y las tradiciones de análisis de las diversas disciplinas de las Ciencias Sociales y las Humanidades.

\section{El turismo tiene una dimensión territorial. ¿qué aportes puede realizar la Geografía para la investigación y enseñanza del hecho turístico?}

Dando continuidad a lo recién señalado, desde la Geografía es posible aportar al conocimiento y comprensión del hecho turístico de maneras significativas. Es verdad (quizás podría decirse que es obvio) que el turismo es un fenómeno que incorpora en forma consustancial la dimensión territorial, en tanto consiste en un desplazamiento territorial de población en búsqueda de satisfactores de necesidades de ocio y recreación desigualmente distribuidos en el territorio. Pero el vínculo con la Geografía no se reduce a esta constatación, ni a inventariar las características de los lugares turísticos. Más que esto, diversos marcos interpretativos válidos en Geografía permiten analizar en profundidad los procesos a través de los cuales los lugares devienen lugares turísticos, la forma en que se valorizan sus atributos como atractivos, las estrategias que los diversos actores sociales despliegan en los distintos lugares y a múltiples escalas para alcanzar sus objetivos, y como consecuencia de todo esto, las transformaciones materiales y simbólicas de los distintos lugares; todo esto en relación directa con el turismo. Creo además que el estudio del turismo aporta también al avance de la Geografía (esto es, hay un vínculo de retroalimentación entre turismo y 
Geografía), en la medida en que permite avances en cuestiones nucleares de la disciplina, como por ejemplo la diferenciación de lugares o los procesos de valorización del territorio a múltiples escalas.

\section{¿Cuáles son las perspectivas teóricas actuales que conside- ran al fenómeno turístico?}

No creo estar en condiciones de dar una respuesta a esta pregunta, pues existen múltiples perspectivas para abordar el hecho turístico. En verdad, debería decirse que en función del aspecto y del problema que se quiere indagar, habrá perspectivas disciplinarias más fértiles que otras para comprender dicho aspecto o problema del turismo.

Si nos concentramos en Geografía, creo que se han realizado avances importantes para ir más allá de las perspectivas descriptivas (sistemáticas y regionales) que fueron predominantes en la geografía del turismo por mucho tiempo. Hoy existen aportes muy interesantes vinculados con abordajes sociales de la Geografía, que ponen acento en cuestiones vinculadas con la desigual distribución de costos y beneficios del turismo en las sociedades, o con las desigualdades en el acceso al turismo y sus diversas modalidades; cuestiones como el derecho al turismo, el turismo de calidad, la reproducción de distinción y de exclusión social a través del turismo, son temas en los que se han realizado avances de gran interés. También las perspectivas culturales en Geografía han aportado bases para el estudio de aspectos sustantivos para la comprensión del fenómeno turístico, tales como la definición social del gusto por ciertos atractivos y lugares (por cierto variables a lo largo del tiempo), el rol de las representaciones (pinturas, narraciones) en la definición de atractivos turísticos, etc.
¿Cómo abordar las temáticas vinculadas al turismo en la geografía escolar? ¿Qué estrategias didácticas se podrían desarrollar?

Nuevamente es difícil responder esta pregunta. Quizás pueda aproximar una respuesta por la vía negativa: en el tratamiento escolar de temas vinculados con el turismo suelen observarse abordajes ingenuos, que apelan fuertemente a la valoración positiva de esta práctica, a su asociación con el ocio y la recreación. No es malo que esto sea así en ciertos niveles de abstracción limitados (por ejemplo para niveles iniciales del sistema educativo), pero debería tenerse mucho cuidado con transferir estas miradas también al análisis del fenómeno turístico que, como cualquier hecho social, no es ingenuo ni permite interpretaciones simples. En todo hecho turístico se procesa poder, sea de tipo económico a través de sus actividades relacionadas, político a través de propuestas de desarrollo o asignación de avales y programas, social a través de la desigual distribución de los servicios turísticos, o culturales a través de la imposición de ciertos gustos y marcas de distinción asignadas a algunos destinos y prácticas turísticas (y, por oposición, negadas a otros), que revierten sobre los individuos que los practican consolidando o reforzando la desigualdad social que, a su vez, tiene dimensión territorial. Estos ejemplos deberían advertir que por detrás de los "bellos paisajes" y de las "merecidas vacaciones" existen temas relevantes para comprender lo social desde la Geografía; nuestras clases deberían orientarse hacia esto, y aunque no siempre podamos alcanzar estos niveles de comprensión, aún en los niveles más básicos los docentes deberíamos tener presentes estas cuestiones, pues nos orientarán para una mejor práctica escolar. 
A modo de reflexión final: icuáles son sus apreciaciones y puntos de vistas acerca de la compresión del turismo como fenómeno multifacético?

Creo que el hecho más importante que ha tenido lugar en los últimos años en relación al estudio del turismo es que se han comprendido sus vastos alcances como fenómeno social y, en consecuencia, se reconoce la necesidad de abordar su análisis en relación con marcos interpretativos más amplios provenientes de diversas disciplinas. Esto permite abandonar tanto visiones ingenuas del fenómeno turístico como visiones que me gusta llamar "excepcionalistas", que explican el turismo desvinculado del resto de lo social y que, en consecuencia, explican muy poco.

Si bien aún hay mucho trabajo por hacer, creo que las cuestiones que acabo de señalar representan avances muy importantes en la comprensión de un tema que, como el turismo, tiene una presencia creciente en nuestras sociedades. 